\title{
Epigenetics of single-site and multi-site atherosclerosis in African Americans from the Genetic Epidemiology Network of Arteriopathy (GENOA)
}

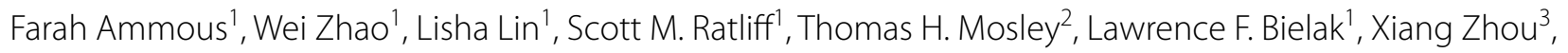
Patricia A. Peyser ${ }^{1}$, Sharon L. R. Kardia ${ }^{1}$ and Jennifer A. Smith ${ }^{1, *^{*}}$

\begin{abstract}
Background: DNA methylation, an epigenetic mechanism modulated by lifestyle and environmental factors, may be an important biomarker of complex diseases including cardiovascular diseases (CVD) and subclinical atherosclerosis.

Methods: DNA methylation in peripheral blood samples from 391 African-Americans from the Genetic Epidemiology Network of Arteriopathy (GENOA) was assessed at baseline, and atherosclerosis was assessed 5 and 12 years later. Using linear mixed models, we examined the association between previously identified CpGs for coronary artery calcification (CAC) and carotid plaque, both individually and aggregated into methylation risk scores (MRS ${ }_{C A C}$ and $M_{\text {Rarotid }}$, and four measures of atherosclerosis (CAC, abdominal aorta calcification (AAC), ankle-brachial index (ABI), and multi-site atherosclerosis based on gender-specific quartiles of the single-site measures). We also examined the association between four epigenetic age acceleration measures (IEAA, EEAA, PhenoAge acceleration, and GrimAge acceleration) and the four atherosclerosis measures. Finally, we characterized the temporal stability of the epigenetic measures using repeated DNA methylation measured 5 years after baseline $(N=193)$.

Results: After adjusting for CVD risk factors, four CpGs (cg05575921 (AHRR), cg09935388 (GFI1), cg21161138 (AHRR), and cg18168448 (LRRC52)) were associated with multi-site atherosclerosis (FDR $<0.1)$. cg05575921 was also associated with $A A C$ and cg09935388 with $A B I$. MRS ${ }_{\text {CAC }}$ was associated with $A B I(B e t a=0.016, P=0.006)$, and MRS $_{\text {carotid }}$ was associated with both AAC (Beta $=0.605$, equivalent to approximately 1.8-fold increase in the Agatston score of AAC, $P=0.004)$ and multi-site atherosclerosis (Beta $=0.691, P=0.002)$. A 5 -year increase in GrimAge acceleration ( 1 SD) was associated with a 1.6-fold $(P=0.012)$ increase in the Agatston score of AAC and 0.7 units $(P=0.0003)$ increase in multi-site atherosclerosis, all after adjusting for CVD risk factors. All epigenetic measures were relatively stable over 5 years, with the highest intraclass correlation coefficients observed for $\mathrm{MRS}_{\text {carotid }}$ and GrimAge acceleration (0.87 and 0.89 , respectively).
\end{abstract}

Conclusions: We found evidence of an association between DNA methylation and atherosclerosis at multiple vascular sites in a sample of African-Americans. Further evaluation of these potential biomarkers is warranted to deepen our understanding of the relationship between epigenetics and atherosclerosis.

*Correspondence: smjenn@umich.edu

${ }^{1}$ Department of Epidemiology, School of Public Health, University of Michigan, Ann Arbor, MI, USA

Full list of author information is available at the end of the article permits use, sharing, adaptation, distribution and reproduction in any medium or format, as long as you give appropriate credit to the original author(s) and the source, provide a link to the Creative Commons licence, and indicate if changes were made. The images or other third party material in this article are included in the article's Creative Commons licence, unless indicated otherwise in a credit line to the material. If material is not included in the article's Creative Commons licence and your intended use is not permitted by statutory regulation or exceeds the permitted use, you will need to obtain permission directly from the copyright holder. To view a copy of this licence, visit http://creativecommons.org/licenses/by/4.0/. The Creative Commons Public Domain Dedication waiver (http://creativeco mmons.org/publicdomain/zero/1.0/) applies to the data made available in this article, unless otherwise stated in a credit line to the data. 
Keywords: Methylation risk score, DNA methylation, Epigenetic age, Atherosclerosis, Calcification

\section{Background}

Cardiovascular diseases (CVD), including coronary heart disease, myocardial infarction, and peripheral artery disease, are the leading cause of death in the USA [1]. The CVD mortality burden is $21 \%$ higher in African-Americans compared to Whites despite modest decreases in racial disparities at the national level since 2005 [2]. Genetic factors, along with non-genetic risk factors, such as age, smoking, and hypertension, contribute to CVD. However, much of the variability in CVD, as well as the persistent causes of CVD disparities, remain unexplained.

Atherosclerosis, a chronic inflammatory age-related condition that develops over several decades, is a precursor for CVD and can occur in either the intimal or medial layers of the arterial wall [3-6]. The intima is the innermost layer consisting of a smooth endothelium layer covered by elastic tissue. The accumulation of lipids and fibrous material in the intima can occur at the coronary arteries and large arteries including the aorta [6]. Coronary artery calcification (CAC) is a strong predictor of incident CVD and coronary heart disease beyond traditional CVD risk factors [7-10]. Medial calcification occurs in the tunica media which consists of smooth muscles cells and elastic fibers. It affects lower limb arteries, in addition to the aorta, and is typically associated with peripheral artery disease [6]. Medial lesions are thought to calcify earlier than intimal ones and result in vascular stiffness and reduced vessel compliance [11, 12], and they may be also associated with CVD $[8,13]$. Medial calcification increases with aging and is prevalent in individuals with chronic kidney disease and diabetes mellitus. The ankle-brachial pressure index ratio (ABI) can be used to assess medial calcification in the peripheral arteries [11].

Epigenetic mechanisms, including DNA methylation (DNAm), capture both genetic influences as well as the imprints of lifestyle and environmental exposures throughout the life course, and may have potential as biomarkers of CVD risk. Epigenetic age acceleration measures are DNA methylation-based markers of biological aging that are associated with late-life onset diseases and mortality [14-18]. Epigenetic age acceleration measures include first generation measures (HorvathAge [14] and HannumAge [15]), trained on chronological age, and more recent measures trained on biological and physiological markers and chronological age, such as PhenoAge [19] and GrimAge [17]. Previous studies of genome-wide DNA methylation profiles or epigenetic age acceleration measures have reported statistically significant associations between epigenetic markers and CVD [20-26]; however, a majority of these studies were in cohorts of European ancestry and/or were cross-sectional rather than longitudinal.

Only a few epidemiological studies have examined the association between DNAm and subclinical CVD or atherosclerosis [27, 28]. A recent cross-sectional transcriptome and epigenome analysis of atherosclerosis in 1208 participants from the Multi-Ethnic Study of Atherosclerosis (MESA) identified 82 differentially methylated $\mathrm{CpGs}$ associated with either $\mathrm{CAC}$ or carotid plaque score at false discovery rate $(\mathrm{FDR}) \leq 0.1$ [27]. The sample was comprised of $45.9 \%$ Caucasians, $21.5 \%$ AfricanAmericans, and 32.6\% Hispanics. Race-specific analyses showed that the directions of the methylation changes were generally consistent across these groups, although some sites were not significant for African-Americans and Hispanics [27]. The most significant CpG associated with carotid plaque, cg05575921, is located in the $A H R R$ gene body and is a well-documented smoking marker [29-32].

In the current study, we evaluated the association between potential epigenetic markers of atherosclerosis and single- or multi-site atherosclerosis, assessed 5 and 12 years later, in 391 African-Americans from the Genetic Epidemiology Network of Arteriopathy (GENOA). Our atherosclerosis measures included CAC, abdominal aorta calcification (AAC), and ABI. Epigenetic markers included the previously identified CpGs for atherosclerosis [27], methylation risk scores (MRSs) derived from these CpGs, and four epigenetic age acceleration measures (Horvath (IEAA) [14], Hannum (EEAA) [15], PhenoAge (PhenoAA) [19], and GrimAge (GrimAA) [17]). Finally, we characterized the temporal stability of the epigenetic age acceleration measures and the MRSs using longitudinal measures of DNA methylation for a subset of the sample $(N=129)$.

\section{Methods \\ Study sample}

GENOA is a community-based study in Rochester, MN and Jackson, MS that was established to identify genes influencing blood pressure [33]. In the first phase of GENOA (Phase I: 1996-2001), sibships with at least two adults with clinically diagnosed essential hypertension before age 60 were recruited, and all siblings in the sibship were invited to participate regardless of hypertension status. Exclusion criteria included secondary 
hypertension, alcoholism or drug abuse, pregnancy, insulin-dependent diabetes mellitus, or active malignancy.

At baseline (Phase I), a total of 1583 non-Hispanic Whites (Rochester, MN) and 1854 African-Americans (Jackson, MS) were enrolled. In the second phase (Phase II: 2001-2005), all participants were invited for a second examination. Eighty percent of African-Americans $(N=1482)$ and $75 \%$ of non-Hispanic Whites $(N=1213)$ from Phase I returned. At Phase III (2009-2011), 752 African-Americans returned for a third examination. Demographic information, medical history, clinical characteristics, lifestyle factors, and blood samples were collected in each phase. This study includes 391 AfricanAmerican participants from 277 sibships who had their DNA methylation measured in whole blood samples collected at Phase I and were seen in Phase III. For a subset of 129 participants that were seen in Phase III, DNA methylation was measured at both Phase I and Phase II. Written informed consent was obtained from all participants and approval was granted by participating institutional review boards (University of Michigan, University of Mississippi Medical Center, and Mayo Clinic).

\section{Study measurements}

Height was measured by stadiometer and weight by electronic balance. Body mass index (BMI) was calculated as weight in kilograms divided by the square of height in meters. Smoking was categorized as current, former, or never. Resting systolic (SBP) and diastolic blood pressure (DBP) were measured by a random zero sphygmomanometer and a cuff appropriate for arm size. The second and third of three readings, after the participant sat for at least five minutes, were averaged for analysis [34]. Hypertension was defined having an average $\mathrm{SBP} \geq 140 \mathrm{mmHg}$ or $\mathrm{DBP} \geq 90 \mathrm{mmHg}$, or current anti-hypertensive medication use. Type 2 diabetes status (T2D) was defined as having fasting blood glucose levels $\geq 126 \mathrm{mg} / \mathrm{dL}$ or self-reported physician-diagnosed diabetes and current diabetes medications use. Serum total cholesterol (TC), high-density lipoprotein cholesterol (HDL-C), and triglycerides (TGs) were measured by standard enzymatic methods on a Hitachi 911 Chemistry Analyzer (Roche Diagnostics, Indianapolis, IN). TC was adjusted for statin use as TC/0.8. Low-density lipoprotein cholesterol (LDLC) was calculated using the Friedewald formula for individuals with TGs below $400 \mathrm{mg} / \mathrm{dl}$ [35].

\section{DNA methylation, epigenetic age acceleration, and methylation risk scores}

Genomic DNA from 1106 African-American participants from Phase I and 304 from Phase II was extracted from stored peripheral blood leukocytes using AutoGen FlexStar (AutoGen, Holliston, MA) and DNA methylation was measured using the Infinium MethylationEPIC BeadChip. DNA methylation processing procedures have been previously described [36]. Briefly, sex mismatches and outliers were excluded using the shinyMethyl $\mathrm{R}$ package [37]. Probes with detection $P$ value $<10^{-16}$ were considered to be successfully detected [38]. Samples and probes that failed a detection rate of at least $10 \%$ were removed. The Noob method was used for individual background and dye-bias normalization [39]. Regression on Correlated Probes method was used to adjust for the probe-type bias in the data [40]. White blood cell type proportions within the blood sample were estimated using Houseman's method [41]. A total of 1100 samples from Phase I and 294 from Phase II were available after quality control.

We derived two MRSs based on the regression coefficients of CpG sites associated with CAC and/or carotid plaque at FDR $\leq 0.1$ in MESA [27]. For CAC, 1 of the 16 CpGs reported in MESA (cg00889709) was not available in GENOA. For carotid plaque, 6 of the 68 CpGs reported in MESA (cg06126421, cg05951221, cg09768249, cg08170227, cg00913954, and cg08882503) were not available in GENOA. Methylation $M$ values were first adjusted for batch effects (modeled as random effects of plate, row, and column) and white blood cell counts (modeled as fixed effects) by adding the residuals from the linear mixed model to the mean DNA methylation of each CpG. These values were then weighted by the previously reported effect sizes [27] and summed over the CpGs to calculate two MRSs, $\mathrm{MRS}_{\mathrm{CAC}}$ based on $15 \mathrm{CpGs}$ and $\mathrm{MRS}_{\text {carotid }}$ based on $62 \mathrm{CpGs}$. Two CpGs (cg07033253 and cg23661483) were associated with both CAC and carotid plaque in MESA and are included in both MRSs. Higher values of MRS correspond to greater risk of atherosclerosis.

Of the 75 total CpGs used to construct the two MRSs, approximately $13 \%$ are in CpG island regions, $33 \%$ in shore/shelf regions, $11 \%$ in promoter regions, $21 \%$ in enhancer regions, $50 \%$ in transcription factor binding sites, and 52\% in DNase hypersensitivity sites. Detailed annotation of the individual CpGs has been previously described [27]. To investigate whether single-nucleotide polymorphisms (SNPs) proximal to the CpG sites may have substantially influenced methylation levels, we examined whether any of the CpGs overlapped with SNPs using the DMRcate package [42]. Out of the 75 CpGs, only 4 CpGs (cg02475408, cg13913475, cg15501219, and cg23848152) had SNPs with a minor allele frequency of at least $1 \%$ within 10 base pairs of the CpG site itself.

For the epigenetic age acceleration estimation, methylation beta values for Phase I and Phase II DNA methylation were uploaded to the online Horvath epigenetic age calculator to calculate DNAm age [43]. Four measures of 
epigenetic age-HorvathAge, HannumAge, PhenoAge, and GrimAge-were estimated. Intrinsic epigenetic age acceleration (IEAA) is based on the regression residuals from a model of chronological age and blood cell counts and HorvathAge as the outcome [14, 44]. Extrinsic epigenetic age acceleration (EEAA) is derived similarly based on the HannumAge but incorporates weighted averages of three white blood cell types (naïve cytotoxic $\mathrm{T}$ cells, exhausted cytotoxic $\mathrm{T}$ cells, and plasmablasts) $[15,44]$. PhenoAA is a residual measure from a model of phenotypic age, calculated based on clinical measures such as albumin, creatinine, and white blood cell counts, as well as chronological age [19]. GrimAA is based on the residuals from a model of GrimAge and chronological age. GrimAge is a composite biomarker of smoking pack-years and seven surrogate measures of plasma proteins selected for their significant association with timeto-death. The components are adrenomedullin (ADM), beta-2-microglobulin, cystatin C, GDF-15, leptin, plasminogen activator inhibitor antigen type 1 (PAI-1), and tissue inhibitor metalloproteinases 1 (TIMP-1) [17].

\section{Gene expression measures}

Gene expression levels in GENOA African-American participants $(N=1233)$ were measured in Epstein-Barr virus (EBV) transformed B-lymphoblastoid cell lines using the Affymetrix Human Transcriptome Array 2.0. Quality control was done using the Affymetrix Expression Console provided by Affymetrix. All array images passed visual inspection and the Affymetrix CEL files were normalized using the Robust Multichip Average algorithm in the Affymetrix Power Tool software [45]. Adjustment for batch effects and other technical covariates was done using Combat [46] and mapping of probes to genes was done using the Brainarray custom CDF version 19 [47]. After quality control, a total of 17,616 autosomal protein coding genes for 1205 participants were available for analysis.

\section{Atherosclerosis measurements}

Computed tomography (CT) imaging conducted at Phase III was used to quantify calcification in the coronary arteries and the abdominal aorta. CT images were read by trained technologists and the amount of calcified plaque was calculated by multiplying each lesion area weighted by attenuation based on the maximum Hounsfield units in the lesion on a TeraRecon Aquarius Workstation (TeraRecon, San Mateo, CA). The amount of calcification was quantified using the Agatston score [48]. Both CAC and abdominal aorta calcification (AAC) were natural log-transformed as $\ln ($ score +1$)$ when examined individually as outcomes.
ABI was used to quantify atherosclerosis in the peripheral arteries. Details about the ABI measurement conducted at Phase II have been previously described [49]. Briefly, a Doppler ultrasonic instrument (Medisonics, Minneapolis, MN) was used to detect the pulse at each arm and ankle using appropriately sized blood pressure cuffs. ABI was calculated as the systolic blood pressure at each ankle site divided by the higher of the two brachial pressures. The lower of the average ABIs from both legs was used. Individuals with $A B I>1.50$ were excluded as they may have non-compressible arteries.

Multi-site atherosclerosis score was defined similarly to that described by Zhao et al. [50]. Both CAC and AAC were scored separately as follows: 0 if not detectable, or for those with detectable calcification as a score between 1 and 4 according to gender-specific quartiles of each measure. $\mathrm{ABI}$ was scored between 0 and 4 for the highest to lowest gender-specific quartiles for $\mathrm{ABI}<1.0,0$ for $1 \leq \mathrm{ABI}<1.4$, and 1 if $\mathrm{ABI} \geq 1.4$ and $\leq 1.50$. The multi-site atherosclerosis score was then calculated as the sum of the three measures (range 0-12) and was modeled as a continuous outcome.

\section{Statistical analysis}

Outliers beyond 5 standard deviations from the mean of the outcome and epigenetic measures were removed. We calculated the Pearson correlation coefficients between the single-site atherosclerosis measures, and among the epigenetic age acceleration measures and MRSs. We also calculated the correlations between the individual GrimAge components and the MRSs.

We used linear mixed models that account for familial relatedness to assess the association between the previously identified atherosclerosis-associated $\mathrm{CpGs}$ in MESA and MRSs derived from these CpGs (predictors) and the single- or multi-site atherosclerosis measures (outcomes). The minimally adjusted model (Model 1) was adjusted for age at baseline, sex, first 4 genetic principal components (PCs), and time between the measures. The time covariate was calculated based on the age difference of the participants at the time of atherosclerosis assessment (Phase II or Phase III) and DNA methylation assessment (Phase I). For models of multi-site atherosclerosis, we included two time covariates-the age difference between Phase III and Phase I, and an additional covariate for the age difference between Phase III and Phase II-to account for the differences in the assessment times of ABI (at Phase II) and CAC and AAC (at Phase III). Model 2 was additionally adjusted for smoking status at baseline, and Model 3 was further adjusted for baseline CVD risk factors (T2D status, hypertension status, BMI, and statin-adjusted total cholesterol levels). 
For CpGs associated with at least one of the atherosclerosis measures in Model 1 at FDR $<0.1$, we investigated for association with cis-gene expression $( \pm 1 \mathrm{Mb}$ for each $\mathrm{CpG}$ ). For that, we fit a linear mixed model adjusted for age, sex, time between measures, and the first 4 genetic PCs. For genes significantly associated with DNA methylation at $\mathrm{FDR}<0.1$, we investigated their association with the atherosclerosis measures using a linear mixed model approach with the same covariates.

We used a similar procedure as described above to assess the association between the four epigenetic age acceleration measures and atherosclerosis, except that genetic PCs were not included as covariates. This approach of not adjusting for genetic PCs is consistent with other studies and allows for comparability of findings. As sensitivity analysis, we also performed this analysis after adjusting for the first four genetic PCs. We additionally carried out sensitivity analyses adjusting for white blood cell counts for significant associations with PhenoAA and GrimAA to assess confounding by changes in blood cell composition [17, 19, 51]. For GrimAA, we investigated the association between the individual GrimAge components and atherosclerosis to identify components that may be driving the association between GrimAA and atherosclerosis or that outperform the overall GrimAA measure itself. For this analysis, GrimAge components were scaled and centered. Models were adjusted for age, sex, time between measures, and white blood cell counts.

For the subset of individuals with repeated DNA methylation measurements, we used chi-square and $t$ tests as appropriate to compare the demographic and clinical characteristics of the subset to individuals without the repeated measurements. We used linear mixed-effect models adjusted for age and sex to calculate the intraclass correlation coefficients (ICC) between Phases I and II for the methylation risk scores and the epigenetic age acceleration measures. Parametric bootstrapping (1000 iterations) was used to calculate the $95 \%$ confidence intervals of the ICC coefficients [52, 53]. Additionally, for these participants, we assessed the associations between all of the epigenetic biomarkers at Phase II and atherosclerosis after adjusting for age, sex, time between measures (when applicable), first 4 genetic principal components, smoking status, hypertension status, diabetes status, body mass index, and total cholesterol levels adjusted for statin use.

Statistical tests were two-sided. False discovery rate (FDR) [54] of 0.1 was considered significant for the associations between the individual CpGs and the atherosclerosis measures. A Bonferroni adjusted $P$ value of $<0.025$ (for MRS association analyses) and $P<0.0125$ (for epigenetic age acceleration association analyses) were considered significant. Analyses were conducted in $\mathrm{R}$ (Version 3.4.1) [55], using the lme4 [56], and rptR [53] packages.

\section{Results}

\section{Sample characteristics}

Baseline characteristics of the participants are shown in Table 1 . The mean age of the participants was 56 years $(\mathrm{SD}=9.0)$ at Phase I. Women comprised about $76 \%$ of the sample. Phase III was on average 12 years $(\mathrm{SD}=1.2)$ after Phase I. About $64 \%$ of the participants had hypertension and $16 \%$ had T2D at Phase I. Distributions of the atherosclerosis measures and MRSs are shown in Additional

Table 1 Descriptive characteristics of GENOA African-Americans

\begin{tabular}{|c|c|}
\hline Characteristics $^{\mathrm{a}}$ & Overall $(N=391)$ \\
\hline Females (\%) & $297(76.0 \%)$ \\
\hline Age at Phase I (years) & $56.0 \pm 9.0$ \\
\hline Age at Phase III (years) & $68.0 \pm 8.4$ \\
\hline \multicolumn{2}{|l|}{ Cardiovascular risk factors at Phase I } \\
\hline \multicolumn{2}{|l|}{ Smoking status } \\
\hline Never (\%) & $241(61.6 \%)$ \\
\hline Former (\%) & $93(23.8 \%)$ \\
\hline Current (\%) & $57(14.6 \%)$ \\
\hline Body mass index $\left(\mathrm{kg} / \mathrm{m}^{2}\right)$ & $31.4 \pm 6.2$ \\
\hline Hypertension & $249(63.7 \%)$ \\
\hline Type 2 diabetes & $63(16.1 \%)$ \\
\hline Total cholesterol ${ }^{\mathrm{b}}(\mathrm{mg} / \mathrm{dl})$ & $208.56 \pm 50.4$ \\
\hline Low-density lipoprotein cholesterol ${ }^{\mathrm{C}}(\mathrm{mg} / \mathrm{dl})$ & $121.8(42.8)$ \\
\hline Statin use (\%) & $18(4.6 \%)$ \\
\hline \multicolumn{2}{|l|}{ Atherosclerosis measures at Phase III } \\
\hline Coronary artery calcification score, median (IQR) & $18.7(0-195.7)$ \\
\hline Abdominal aorta calcification score, median (IQR) & $500.8(18.9-1800.5)$ \\
\hline Ankle-brachial index, median (range) ${ }^{d}$ & $0.985(0.474-1.274)$ \\
\hline $\begin{array}{l}\text { Multi-site atherosclerosis score, median (IQR) (range } \\
0-12 \text { ) }\end{array}$ & $5(2-7)$ \\
\hline \multicolumn{2}{|l|}{ Methylation risk scores at Phasel } \\
\hline MRS $_{C A C}{ }^{e}$ & $0.92 \pm 0.85$ \\
\hline $\mathrm{MRS}_{\text {carotid }}$ & $-3.52 \pm 0.81$ \\
\hline \multicolumn{2}{|l|}{ DNAm age measures at Phasel } \\
\hline HorvathAge (years) & $52.8 \pm 8.9$ \\
\hline HannumAge (years) & $46.2 \pm 9.5$ \\
\hline PhenoAge (years) & $42.7 \pm 11.5$ \\
\hline GrimAge (years) & $52.8 \pm 7.9$ \\
\hline
\end{tabular}

IQR interquartile range, DNAm DNA methylation

${ }^{\text {a }}$ Means \pm standard deviation

${ }^{\mathrm{b}}$ Adjusted for statin use as total cholesterol/0.8

'Calculated using the Friedewald formula for participants with triglycerides $<400 \mathrm{mg} / \mathrm{dl}(\mathrm{N}=386)$

$\mathrm{d}$ Measured at Phase II (mean: $5.2 \pm 1.3$ years from Phase I)

${ }^{\mathrm{e}} N=390$, after removing one outlier beyond 5 standard deviation units from the mean 
file 1: Figs. S1 and S2, respectively. For $\mathrm{MRS}_{\mathrm{CAC}}$, one outlier beyond $5 \mathrm{SD}$ from the mean was removed from the analysis.

\section{Correlations among the atherosclerosis measures, epigenetic age acceleration measures, and methylation risk scores}

$\mathrm{CAC}$ and AAC were correlated at $r=0.57$ $\left(P<2.2 \times 10^{-16}\right)$. ABI was negatively correlated with AAC $(r=-0.14, P=0.004)$, but only weakly correlated with CAC $(r=-0.08, P=0.09)$. Additional file 1: Table S1 shows the correlation between the epigenetic predictors. The correlation between the acceleration measures was weak to moderate ( $r$ range $0.21-0.46$ ). The two MRSs were correlated at $r=0.32\left(P=1.55 \times 10^{-10}\right)$. Most of the epigenetic age acceleration measures and MRSs were weakly correlated ( $r$ range 0.09-0.29), except for Gri$\mathrm{mAA}$ and $\mathrm{MRS}_{\text {carotid }}$ which were correlated at $r=0.68$ $\left(P=2.2 \times 10^{-16}\right)$. Scatterplots of the MRSs against the epigenetic age acceleration measures are shown in Additional file 1: Fig. S3. Of the GrimAge components, smoking pack-years was slightly more correlated with $\mathrm{MRS}_{\text {carotid }}$ than the overall GrimAA measure $(r=0.75$, $\left.P=2.2 \times 10^{-16}\right)$, with the second highest correlation between $\mathrm{MRS}_{\text {carotid }}$ and PAI-1 $\left(r=0.26, P=2.9 \times 10^{-7}\right)$.

\section{Associations between previously identified atherosclerosis-associated $\mathrm{CpGs}$, cis-gene expression, and atherosclerosis}

$\mathrm{CAC}, \mathrm{AAC}, \mathrm{ABI}$, and multi-site atherosclerosis were associated with 21, 15, 14, and 42 CpGs in Model 1, respectively $(F D R<0.1)$. The significant regression results are shown in Additional file 1: Table S2. The majority of these sites were carotid plaque-associated CpGs in MESA. Additional file 1: Table S3 shows the regression results for the $\mathrm{CpGs}$ that remained significantly associated with atherosclerosis after adjustment for CVD risk factors (Model 3) in GENOA. After adjusting for CVD risk factors, 4 CpGs (cg05575921 (AHRR), cg09935388 (GFI1), cg21161138 (AHRR), and cg18168448 (LRRC52)) remained significantly associated with multi-site atherosclerosis. CpG cg05575921 was also associated with AAC and cg09935388 with ABI $(F D R<0.1)$. All of these CpGs were carotid plaqueassociated CpGs in MESA. Hypermethylation at all of the significant CpGs (FDR $<0.1$ in Model 3) was associated with decreased multi-site atherosclerosis. Significant CpGs in Model 3 explained between 5.5\% and $11.2 \%$ of the variability of multi-site atherosclerosis, cg05575921 explained $6.9 \%$ of the variability of AAC, and $\operatorname{cg} 09935388$ explained $11.1 \%$ of the variability in ABI.
To investigate any regulatory effects on gene expression by the significant CpGs, we examined the association between CpGs shown in Additional file 1 : Table S1 and cis-gene expression ( $\pm 1 \mathrm{Mb})$. DNA methylation at $\operatorname{cg} 18168448$ was associated with decreased expression of $A L D H 9 A 1$ and increased expression of ENSG00000236364 at FDR $<0.1$ (Additional file 1: Table S4). Increased $A L D H 9 A 1$ expression was associated with higher CAC $(P=0.005)$ and marginally higher multi-site atherosclerosis $(P=0.054)$. DNA methylation at cg03636183 was associated with decreased gene expression of $F 2 R L$ which was associated with CAC $(P=0.017)$.

\section{Associations between methylation risk scores and atherosclerosis}

Table 2 shows the associations between $\mathrm{MRS}_{\mathrm{CAC}}$ and $\mathrm{MRS}_{\text {carotid }}$ and single- or multi-site atherosclerosis measures. The beta coefficients shown correspond to the change in the atherosclerosis measures associated with a 1-unit increase in MRS. In Model 1, $\mathrm{MRS}_{\mathrm{CAC}}$ was associated with log-transformed AAC (Beta $=0.364,95 \% \mathrm{CI}$ $0.050-0.778, P=0.023)$ but the association was not significant after adjusting for CVD risk factors (Models 2 and 3). $M S_{C A C}$ was associated with higher $A B I$, indicative of less peripheral artery disease, and the associations were significant after adjusting for CVD risk factors (Beta $=0.016,95 \%$ CI 0.004-0.028, $P=0.006$ in Model 3). The MRS $_{\text {CAC }}$ explained $1.2 \%, 1.9 \%, 14.8 \%$, and $0.8 \%$ of the variability of $\mathrm{CAC}, \mathrm{AAC}, \mathrm{ABI}$, and multi-site atherosclerosis after adjusting for CVD risk factors.

$\mathrm{MRS}_{\text {carotid }}$ was associated with all of the atherosclerosis measures in Model 1 (Table 2). Associations remained significant for AAC after adjusting for smoking (Model 2) and other traditional CVD risk factors (Model 3), where a one unit increase in $\mathrm{MRS}_{\text {carotid }}$ was associated 0.605 units increase in log-transformed AAC (95\%CI 0.197-1.013). This is equivalent to an approximately 1.8-fold increase in the Agatston score of AAC. Similarly, the associations between $\mathrm{MRS}_{\text {carotid }}$ and multi-site atherosclerosis remained significant after adjusting for CVD risk factors. A one unit increase in $\mathrm{MRS}_{\text {carotid }}$ was associated with approximately 0.7 units (95\%CI $0.25-1.13)$ increase in the multi-site atherosclerosis score after adjusting for CVD risk factors (Model 3). The $\mathrm{MRS}_{\text {carotid }}$ explained $7.8 \%, 5.3 \%, 2.1 \%$, and $9.4 \%$ of the variability of CAC, $\mathrm{AAC}, \mathrm{ABI}$, and multi-site atherosclerosis after adjusting for CVD risk factors. 
Table 2 Association between methylation risk scores and atherosclerosis measures in GENOA African-Americans

\begin{tabular}{|c|c|c|c|c|c|c|c|c|c|c|}
\hline \multirow[t]{2}{*}{ Outcome } & \multirow{2}{*}{$\begin{array}{l}\text { Methylation } \\
\text { risk score }\end{array}$} & \multicolumn{3}{|l|}{ Model 1} & \multicolumn{3}{|l|}{ Model 2} & \multicolumn{3}{|l|}{ Model 3} \\
\hline & & Beta & SE & $P$ & Beta & SE & $P$ & Beta & SE & $P$ \\
\hline \multirow[t]{2}{*}{ Coronary artery calcification score (CAC) a } & $\mathrm{MRS}_{\mathrm{CAC}}$ & 0.262 & 0.146 & 0.074 & 0.153 & 0.173 & 0.295 & 0.138 & 0.139 & 0.318 \\
\hline & $\mathrm{MRS}_{\text {carotid }}$ & 0.700 & 0.155 & $8.66 \times 10^{-6}$ & 0.425 & 0.199 & 0.033 & 0.411 & 0.191 & 0.032 \\
\hline \multirow[t]{2}{*}{ Abdominal aorta calcification score (AAC) ${ }^{a}$} & $\mathrm{MRS}_{\mathrm{CAC}}$ & 0.364 & 0.160 & 0.023 & 0.175 & 0.154 & 0.258 & 0.173 & 0.151 & 0.252 \\
\hline & $\mathrm{MRS}_{\text {carotid }}$ & 1.046 & 0.167 & $1.10 \times 10^{-9}$ & 0.580 & 0.211 & 0.006 & 0.605 & 0.208 & 0.004 \\
\hline \multirow[t]{2}{*}{ Ankle-brachial index (ABI) } & $\mathrm{MRS}_{\mathrm{CAC}}$ & 0.013 & 0.006 & 0.025 & 0.015 & 0.006 & 0.008 & 0.016 & 0.006 & 0.006 \\
\hline & $\mathrm{MRS}_{\text {carotid }}$ & -0.014 & 0.006 & 0.021 & -0.009 & 0.008 & 0.275 & -0.007 & 0.008 & 0.400 \\
\hline \multirow[t]{2}{*}{ Multi-site atherosclerosis score } & $\mathrm{MRS}_{\mathrm{CAC}}$ & 0.317 & 0.170 & 0.064 & 0.145 & 0.165 & 0.382 & 0.127 & 0.162 & 0.433 \\
\hline & $\mathrm{MRS}_{\text {carotid }}$ & 1.165 & 0.177 & $1.65 \times 10^{-10}$ & 0.718 & 0.225 & 0.002 & 0.691 & 0.223 & 0.002 \\
\hline
\end{tabular}

Model 1 is adjusted for age, sex, time between measures, and the first 4 genetic principal components

Model 2 is adjusted for Model 1 covariates and smoking status

Model 3 is adjusted for Model 2 covariates, hypertension status, diabetes status, body mass index, and total cholesterol levels adjusted for statin use

Beta is the change in the atherosclerosis measure associated with a 1 unit increase in the MRS

$P$ values significant after Bonferroni correction $(P<0.025)$ are shown in bold font

${ }^{\text {a }}$ Coronary artery and abdominal aorta calcification scores were transformed as $\ln [(C A C+1)]$ and $\ln [(A A C+1)]$

\section{Associations between epigenetic age acceleration and atherosclerosis}

Associations between the epigenetic age acceleration measures and atherosclerosis are shown in Table 3. PhenoAA was associated with multi-site atherosclerosis in Model 1, but the association attenuated after adjusting for CVD risk factors. GrimAA was positively associated with all measures of atherosclerosis in the minimally adjusted model (Model 1) and remained significant after adjusting for CVD risk factors for AAC and multi-site atherosclerosis. A 5-year increase in GrimAA $(\sim 1 \mathrm{SD})$ was associated with a 1.6-fold (95\%CI 1.11-2.25) increase in the Agatston score of AAC and 0.7 units (95\%CI 0.33-1.07) increase in multi-site atherosclerosis score in Model 3. Increased GrimAA was nominally associated with lower ABI (higher atherosclerosis), but the association was not significant after accounting for multiple testing. The effect estimates were unchanged after adjusting for the first 4 PCs. Additional file 1: Table S5 shows the associations for PhenoAA and GrimAA after adjusting for white blood cell counts. The associations between GrimAA and AAC and multi-site atherosclerosis in Model 3 slightly attenuated after adjusting for white blood cells counts but remained significant at $P<0.05$.

The associations between the DNA methylation-based surrogate measures comprising GrimAge and atherosclerosis are shown in Additional file 1: Table S6. Associations were adjusted for age, sex, time between measures, and white blood cell counts. All components were associated with at least one single- or multi-site atherosclerosis measure, with the exception of leptin and TIMP-1 $(P<0.05)$. DNAm smoking pack-years was associated with each of the atherosclerosis measures and was the most significant predictor of $\mathrm{CAC}, \mathrm{AAC}$, and multi-site atherosclerosis, with consistent direction of effects across all of the measures. Compared to the corresponding model of GrimAA (Additional file 1: Table S3; Model 1), DNAm smoking pack-years was more significantly associated with single- and multi-site atherosclerosis, with greater magnitude of effects, than the overall GrimAA measure.

\section{Longitudinal correlation of methylation risk scores and epigenetic age acceleration measures between Phases I and II}

Compared to the remaining sample, the 129 individuals with longitudinal measures of DNA methylation were younger (mean age of 53.4 vs. 57.3 years, $P<0.001$ ), had a lower multi-site atherosclerosis score (mean of 4.51 vs. 5.26, $P=0.026$ ) and a lower PhenoAA (mean of -1.11 vs. $0.41, P=0.043)$. All the remaining epigenetic and atherosclerosis measures were similar across both samples $(P>0.05)$. The mean time difference between the DNA methylation measurements was 5.5 years (standard deviation $=1.1$ years, range $2.5-7.4$ ). All of the epigenetic measures were relatively stable between Phases I and II, with both $\mathrm{MRS}_{\text {carotid }}$ and GrimAA showing the highest stability $(\mathrm{ICC}>0.8$ ) (Table 4$)$. $\mathrm{MRS}_{\text {carotid }}$ derived at Phase II was associated with consistent effect direction and larger effect magnitude for log-transformed AAC (Beta $=1.08,95 \%$ CI 0.380-1.78, $P=0.003)$ and was marginally associated with multi-site atherosclerosis (Beta $=0.811,95 \%$ CI $0.090-1.53, P=0.030$ ) compared to the full sample analysis using Phase I MRSs (Table 2, Model 3). Neither MRS was associated with CAC or ABI at Phase II (Additional file 1: Table S7). Additionally, 


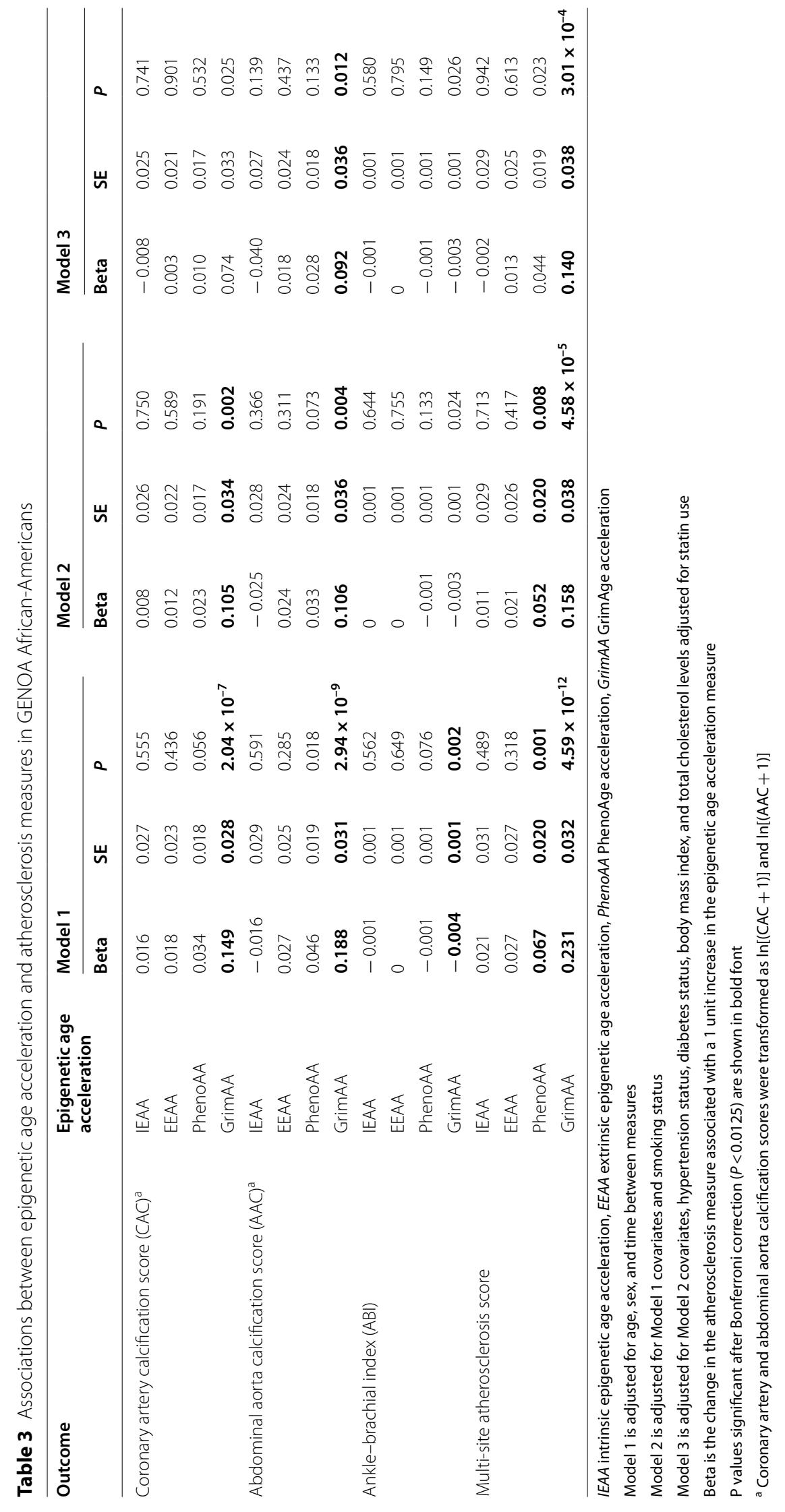


Table 4 Inter-individual correlations for the epigenetic measures (Phases I and II) in GENOA African-Americans ( $N=129)$

\begin{tabular}{ll}
\hline Measures & $\begin{array}{l}\text { Intraclass correlation } \\
\text { coefficient }(\mathbf{9 5} \% \mathbf{C l})\end{array}$ \\
\hline MRS $_{\text {CAC }}$ & $0.771(0.689-0.833)$ \\
MRS $_{\text {carotid }}$ & $0.867(0.821-0.905)$ \\
IEAA & $0.726(0.635-0.802)$ \\
EEAA & $0.799(0.726-0.854)$ \\
PhenoAA & $0.676(0.569-0.758)$ \\
GrimAA & $0.888(0.848-0.921)$ \\
\hline
\end{tabular}

IEAA intrinsic epigenetic age acceleration, EEAA extrinsic epigenetic age acceleration, PhenoAA PhenoAge acceleration, GrimAA GrimAge acceleration

none of the epigenetic age acceleration measures at Phase II were associated with atherosclerosis.

\section{Discussion}

In this study of African-Americans with a high prevalence of hypertension, we examined the association between peripheral blood DNA methylation patterns, measured at baseline, and multi-site atherosclerosis assessed five and 12 years later. After adjusting for CVD risk factors, a total of $4 \mathrm{CpGs}$ were associated with multisite atherosclerosis, with one of them additionally associated with ABI (cg09935388) and another associated with AAC (cg05575921). DNA methylation at cg18168448 was associated with cis-gene expression changes that were also associated with CAC in GENOA. An aggregate risk score of CpGs, MRS $\mathrm{CAC}_{\mathrm{C}}$, was associated with $\mathrm{ABI}$ and $\mathrm{MRS}_{\text {carotid }}$ was associated with AAC and multi-site atherosclerosis after adjusting for CVD risk factors. Gri$\mathrm{mAA}$ was the only epigenetic age acceleration measure associated with atherosclerosis. GrimAA and $\mathrm{MRS}_{\text {carotid }}$ were moderately correlated with each other, and both measures were relatively stable over 5 years in a small subset of participants with repeated DNA methylation measurement. Our findings show evidence of association between DNA methylation sites, previously identified in a cross-sectional analysis, and atherosclerosis assessed 5 and 12 years later. Additionally, our findings show evidence of overlap in the association between these CpGs and atherosclerosis at different vascular sites. We also report an association between age-related methylation changes, as measured by the epigenetic clocks, and vascular calcification.

After adjusting for CVD risk factors, four CpG was associated multi-site atherosclerosis at $\mathrm{FDR}<0.1$. The direction of effects between the individual CpG sites and atherosclerosis in our study were consistent with MESA, where hypomethylation was associated with increased carotid plaque [27]. All 4 CpGs are in gene body regions. Both cg05575921 and cg21161138 are at transcription factor binding sites. CpG cg05575921 maps to an enhancer chromatin state and cg21161138 to a weak repressed chromatin state in primary mononuclear cells from peripheral blood (E062) using chromHMM tracks from Roadmap Epigenomics [57, 58]. CpG cg09935388 maps to a CpG island, a DNase hypersensitive hotspot, and a weak transcribed chromatin state while $\operatorname{cg} 18168448$ maps to a repressed chromatin state $[57,58]$.

Three of the significant CpGs (cg05575921, cg09935388, and cg21161138) were previously found to be associated with smoking [29-32]. When we examined the methylation levels of these three CpGs by smoking status in GENOA, we observed a dose response association where current smokers had the lowest methylation levels and never smokers had the highest methylation levels (Additional file 1: Fig. S4). Both cg05575921 and cg21161138 are located in the AHRR gene body. AHRR is an aryl hydrocarbon receptor repressor, which among other roles, inhibits the metabolism of polycyclic aromatic hydrocarbons and dioxins by competing with AHR $[59,60]$. The significant association between these CpGs and atherosclerosis after adjusting for smoking status in our study could potentially be related to residual confounding, errors in self-reporting of smoking, and/ or inter-individual sensitivities to smoking with lasting biological effects. In a previous analysis in MESA that used a candidate gene approach to assess the association between CpGs in AHRR and atherosclerosis, hypomethylation at $\operatorname{cg} 05575921\left(P=3.08 \times 10^{-10}\right)$ and $\operatorname{cg} 21161138$ $\left(P=7.73 \times 10^{-8}\right)$ was significantly associated with carotid plaque score [61]. Similar to our findings, the association with cg05575921 in MESA remained significant after adjusting for self-reported smoking exposure, urinary cotinine, and other CVD risk factors, and remained significant in stratified analysis of former smokers and current smokers but not never smokers. Other studies have also reported evidence of cg05575921 differential methylation by air pollution in adults [62], by maternal smoking in neonates $[63,64]$, and by smoking in atherosclerotic plaque specimens [65]. Similarly, cg09935388, located in the growth factor independent 1 transcriptional repressor gene (GFI1) gene body region, has been found to be associated with smoking $[32,66,67]$ and exposure to maternal smoking in fetuses $[68,69]$. GFI1 encodes a nuclear zinc finger protein that plays a role in hematopoiesis, oncogenesis, and in controlling histone modification as part of a complex with other cofactors [70,71].

DNA methylation at cg18168448 was also associated with significantly higher multi-site atherosclerosis $(\mathrm{FDR}=0.063)$. The direction of association was consistent for the single-site atherosclerosis measures although 
it did not reach statistical significance. CpG cg18168448 is located in the first exon region of the leucine-rich repeatcontaining protein 52 (LRRC52), which plays a role in the regulation of voltage-gated potassium channel activity. We found evidence of cis-gene expression changes at this CpG, cg18168448, in addition to cg03636183. Our findings in EBV transformed B-lymphoblastoid cell lines are complimentary to those reported previously in monocytes [27]. DNA methylation at cg18168448 was associated with decreased expression of the aldehyde dehydrogenase 9 family member A1 (ALDH9A1) and increased expression of ENSG00000236364, which is antisense to UCK2. ALDH9A1 encoded enzyme has high activity for oxidation of gamma-aminobutyraldehyde and other amino aldehydes. UCK2 encodes a pyrimidine ribonucleoside kinase, which catalyzes the phosphorylation of uridine and cytidine. DNA methylation at cg0363183 located in the body region of F2R like thrombin or trypsin receptor 3 (F2RL3) was associated with significant decreased gene expression of that gene. F2RL3 plays a role in blood coagulation and inflammation, and methylation at cg0363183 has been previously found to be associated with smoking [72], cardiometabolic traits [73], coronary artery disease [74], and morality [75]. The genes corresponding to the 4 significant CpGs and those identified in the cis-gene expression analysis are expressed in low to medium levels in multiple tissue types, with the exception of $L R R C 52$ which is mainly expressed in the testis [76]. AHRR, GF1, ALDH9A1, ENSG00000236364, and F2RL3 have at least a low level of expression in the arteries, heart, and whole blood.

In our study, $\mathrm{MRS}_{\mathrm{CAC}}$ was associated with $\mathrm{AAC}$ and $\mathrm{ABI}$ and the association fully attenuated after adjusting for CVD risk factors for AAC. MRS carotid was associated with all of the atherosclerosis measures in Model 1 and AAC and the derived multi-site atherosclerosis scores remained significant after adjusting for CVD risk factors. Two of the significant CpGs in MRS $\mathrm{Marotid}_{\text {explained }}$ a slightly higher percent of the variability of multi-site atherosclerosis compared to that explained by $\mathrm{MRS}_{\text {carotid, }}$ potentially due to added noise generated by including CpGs not as strongly associated with atherosclerosis in African-Americans. It is not clear why carotid plaqueassociated CpGs were better predictors of atherosclerosis than $\mathrm{CAC}$-associated ones in our sample. One notable finding in MESA was that both the transcriptome signature of AT-rich interaction domain 5B (ARID5B) and a cg25953130 site in the gene were associated with CAC and carotid plaque atherosclerosis measures [27]. In GENOA, cg25953130 was only nominally associated with multi-site atherosclerosis after adjusting for CVD risk factors (Beta $=-0.596,95 \% \mathrm{CI}-0.063$ to -1.13 , $P=0.029$ ), but the effect direction was consistent across studies. In MESA, out of seven CpGs associated with CAC $(F D R<0.05)$ in the full sample, only 3 were significant in the African-American sub-sample, although the magnitude and direction of effect were consistent across ancestry groups. Also, despite having similar age distributions, MESA multi-ethnic participants had a higher median CAC score than African-Americans in GENOA, and MESA had also a lower percentage of females. The prevalence of CAC in GENOA was low (median: 18.7 and IQR 0-195.7) with about $40 \%$ of the sample having an Agatston score of zero. In MESA, participants had a median CAC score of 46 (IQR 0-305), and the proportion with no detectable CAC was not reported. This is consistent with evidence from epidemiological studies showing that African-Americans tend to have lower calcification in the coronary arteries compared to Whites [77-79]. Hence, the CpGs included in the $\mathrm{MRS}_{\mathrm{CAC}}$ could be related to a more extreme form of the trait versus the lower atherosclerosis burden seen in GENOA. Another difference between MESA and GENOA is that the methylation signature in MESA was measured in monocytes, which have a well-established role in atherogenesis [80, 81], while the DNA methylation in GENOA was measured in all white blood cells. This could have the effect of diluting the associations observed in MESA if some cell types have different methylation patterns compared to monocytes. Additionally, the ICC of $\mathrm{MRS}_{\mathrm{CAC}}$ was low, which could indicate a lower stability of methylation at these sites. This could be particularly relevant to GENOA, as we assessed the association with CAC 12 years after DNA methylation measurement, while in MESA methylation and atherosclerosis were assessed concurrently.

GrimAA was the only epigenetic age acceleration measure associated with atherosclerosis in GENOA after adjusting for CVD risk factors. Increased GrimAA, indicative of increased biological aging, was associated with higher atherosclerosis. Very few other studies have examined epigenetic age associations with subclinical measures of CVD. In a cross-sectional analysis of 2500 African-Americans from the Atherosclerosis Risk in Communities (ARIC) study, a 5-year increase in both the Horvath and the Hannum acceleration measures was associated with an approximately $0.01 \mathrm{~mm}$ increase in carotid intima thickness [28]. We did not find associations between the Horvath and Hannum measures we evaluated (IEAA and EEAA) and atherosclerosis. Epigenetic aging measures include different $\mathrm{CpG}$ sites, differ in how they were trained, and are hypothesized to capture different biological processes and aspects of aging $[16,51]$. Both GrimAA and PhenoAA were trained using longitudinal data, making them better predictors of aging-related outcomes [82, 83]. Two recent studies of 
participants of European ancestry have found that GrimAA outperforms the other acceleration measures in its association with incident CVD $[25,26]$ and all-cause mortality $[25,84]$. Our reported associations attenuated slightly after adjusting for white blood cell counts but remained significant, suggesting that the effects were not mediated by blood cell composition. In our study, GrimAA was correlated with $\mathrm{MRS}_{\text {carotid }}$, with the smoking pack-years component of GrimAge being slightly more correlated with $\mathrm{MRS}_{\text {carotid }}$ than the overall GrimAA measure. While we do not know the individual CpGs comprising GrimAge, we know of one CpG overlap, cg05575921, between GrimAge and MRS carotid, and potentially other smoking-related CpGs, which may explain the observed correlations [17].

Our results show that the epigenetic measures most strongly associated with atherosclerosis, GrimAA and $\mathrm{MRS}_{\text {carotid }}$, had moderate stability (ICC: 0.822 and 0.888 , respectively) across repeated samples taken approximately 5 years apart. The characteristic of reliability over time is an important consideration for biomarkers that may be used for risk prediction. Further studies are needed to fully characterize the longitudinal patterns of DNA methylation, especially in response to known drivers of DNA methylation changes, such as smoking. In GENOA, smoking status was unchanged for the majority of the sample between Phases I and III, with only 27 current smokers becoming former smokers. One study that looked at the longitudinal changes of fetal DNA methylation in response to maternal smoking using serial samples at birth, age 7, and age 17 found evidence of reversible methylation changes at cg09935388 (GFI1) and persistent methylation changes at $\operatorname{cg} 05575921(A H R R)$ [69]. An epigenome-wide study of adult smoking reported that out of approximately $2600 \mathrm{CpGs}$ that were differentially methylated between current versus never smokers, 185 CpGs showed patterns of persistent methylation changes between former versus never smokers, including cg05575921, cg09935388, and cg21161138 CpGs [85]. Most recently, Dugue et al. reported a reversibility coefficient (ratio of regression coefficients comparing former to current smokers and never to current smokers) between 69 and 75\% at cg05575921, cg09935388, and cg21161138 [86]. Little is known regarding the longitudinal trends of GrimAA; however, a longitudinal trend of increased GrimAA with increasing age has been observed in one study [87].

One strength of our study is that we examined atherosclerosis at multiple vascular sites which reflect both intimal and medial vascular changes that may manifest differentially over time. CAC has been more extensively studied because it appears in a more clinically relevant vascular site [88] and is more strongly associated with coronary disease compared to carotid intima thickness [89]. Abdominal aorta atherosclerosis has been less extensively studied, yet evidence suggests that the associations of CAC and AAC with CVD are independent and additive $[8,13]$. AAC starts earlier in life, is more prevalent than $\mathrm{CAC}$, and may be associated with an increased risk of onset and progression of CAC and/or lower $\mathrm{ABI}$ [90, 91]. Given the low prevalence of $C A C$ and previous findings that it may not carry the same pathobiological significance in African-Americans [92], incorporating extracoronary calcification may be informative and useful for risk assessment.

A limitation of our study is the attrition of participants between Phases I and III. In a previous work, we have noted that participants who were lost to follow-up had higher epigenetic age acceleration and higher CVD risk [93]. Additionally, we did not have measures of carotid plaque which was included in the multi-site atherosclerosis score that we used as a model for our score in GENOA [50], and the GENOA atherosclerosis measures were not all assessed concurrently. Additionally, seven significant CpGs from MESA were not available in GENOA because of the different arrays used. Further, we only examined cis-gene expression associated with DNA methylation, and thus did not capture trans-regulatory effects. Finally, gene expression was assayed in EBV transformed B-lymphoblastoid cell lines, which may not accurately reflect gene expression patterns in the white blood cells in which DNA methylation was measured. Previous findings show that significant differences exist in the DNA methylation profiles of EBV transformed lymphoblastoid cell lines and peripheral blood [94-96]. As such, gene expression profiles may also differ [95, 97], and our findings should be interpreted with caution.

\section{Conclusions}

In conclusion, our study found evidence of associations between DNA methylation and atherosclerosis at multiple vascular sites after accounting for traditional CVD risk factors. DNA methylation changes were at CpGs with previously reported smoking-related changes. Despite being derived from CpGs associated with carotid plaque, $\mathrm{MRS}_{\text {carotid }}$ was associated with atherosclerosis in the coronary arteries and abdominal aorta suggesting common pathobiological mechanisms of atherosclerosis on a systemic level. One epigenetic aging measure, GrimAA, was also associated with multi-site atherosclerosis beyond traditional CVD risk factors. This is one of the very few studies to examine the DNA methylation signature of multiple atherosclerosis measures in a population-based cohort comprised solely of AfricanAmericans. These results further our understanding of the relationship between epigenetics, biological aging, 
and atherosclerosis. Future work in this area, including in other racial groups, may lead to the identification of potential biomarkers of atherosclerosis, lead to better identification of those at increased risk for atherosclerosis, and further help delineate causes of cardiovascular disease disparities across populations.

\begin{abstract}
Abbreviations
AAC: Abdominal aorta calcification; ABI: Ankle-brachial index; ADM: Adrenomedullin; BMI: Body mass index; CAC: Coronary artery calcification; CT: Computed tomography; CVD: Cardiovascular disease; DBP: Diastolic blood pressure; EEAA: Extrinsic epigenetic age acceleration; FDR: False discovery rate; GENOA: Genetic Epidemiology Network of Arteriopathy; ICC: Intraclass correlation coefficient; IEAA: Intrinsic epigenetic age acceleration; LDL-C: Lowdensity lipoprotein cholesterol; MESA: Multi-Ethnic Study of Atherosclerosis; MRS: Methylation risk score; PAI-1: Plasminogen activator inhibitor antigen type 1; PC: Principal component; SBP: Systolic blood pressure; SD: Standard deviation; TC: Total cholesterol; TIMP-1: Tissue inhibitor metalloproteinases 1; T2D: Type 2 diabetes
\end{abstract}

\section{Supplementary Information}

The online version contains supplementary material available at https://doi. org/10.1186/s13148-022-01229-3.

Additional file 1: Supplementary material, including Supplemental Tables 1-7 and Supplemental Figures 1-4.

\section{Acknowledgements}

The authors wish to thank the staff and participants of the GENOA study.

\section{Authors' contributions}

FA and JAS conceived and designed the study and wrote and revised the manuscript. FA conducted analyses, with assistance from WZ, LL, SMR, and XZ. WZ cleaned the methylation data. THM, PAP, SLRK, and LFB oversaw data collection at all phases of GENOA and assisted with designing the study. JAS supervised the study and provided funding for analysis. All authors read and approved the final manuscript.

\section{Funding}

Support for the Genetic Epidemiology Network of Arteriopathy (GENOA) was provided by the National Heart, Lung and Blood Institute (U01HL054457, RC1HL100185, R01HL085571, R01HL119443, R01HL141292, and R01HL133221) and the National Institute of Neurological Disorders and Stroke (R01NS041558). Funding agencies played no role in study design, data collection, analysis, interpretation of results, or writing the manuscript.

\section{Availability of data and materials}

For this analysis, phenotype data are from the Database of Genotypes and Phenotypes (dbGaP): phs001401.v2.p1. Methylation data are from the Gene Expression Omnibus (GEO): GSE157131. Due to IRB restriction, mapping of the sample IDs between genotype data (dbGaP) and methylation data (GEO) cannot be provided publicly but is available upon written request to JAS and SLRK.

\section{Declarations}

\section{Ethics approval and consent to participate}

Written informed consent was obtained from all participants, and Institutional Review Boards at the University of Michigan, University of Mississippi Medical Center, and Mayo Clinic approved this study.

\section{Consent for publication}

Not applicable.

\section{Competing interests}

The authors declare that they have no competing interests.

\section{Author details}

${ }^{1}$ Department of Epidemiology, School of Public Health, University of Michigan, Ann Arbor, MI, USA. ${ }^{2}$ Memory Impairment and Neurodegenerative Dementia (MIND) Center, University of Mississippi Medical Center, Jackson, MS, USA. ${ }^{3}$ Department of Biostatistics, School of Public Health, University of Michigan, Ann Arbor, MI, USA. ${ }^{4}$ Survey Research Center, Institute for Social Research, University of Michigan, Ann Arbor, MI, USA.

Received: 1 November 2021 Accepted: 5 January 2022

Published online: 17 January 2022

\section{References}

1. Virani SS, Alonso A, Aparicio HJ, Benjamin EJ, Bittencourt MS, Callaway CW, et al. Heart disease and stroke statistics-2021 update: a report from the American Heart Association. Circulation. 2021;143(8):e254-743.

2. Van Dyke M, Greer S, Odom E, Schieb L, Vaughan A, Kramer M, et al. Heart disease death rates among blacks and whites aged $\geq 35$ years_-United States, 1968-2015. MMWR Surveill Summ. 2018;67(5):1.

3. Ross R. Atherosclerosis_-an inflammatory disease. z Engl J Med. 1999;340(2):115-26.

4. Libby P, Buring JE, Badimon L, Hansson GK, Deanfield J, Bittencourt MS, et al. Atherosclerosis. Nat Rev Dis Primers. 2019;5(1):56.

5. Frostegard J. Immunity, atherosclerosis and cardiovascular disease. BMC Med. 2013;11:117

6. Mackey RH, Venkitachalam L, Sutton-Tyrrell K. Calcifications, arterial stiffness and atherosclerosis. Adv Cardiol. 2007:44:234-44.

7. Criqui MH, Langer RD, Fronek A, Feigelson HS, Klauber MR, McCann TJ, et al. Mortality over a period of 10 years in patients with peripheral arterial disease. N Engl J Med. 1992;326(6):381-6.

8. Criqui MH, Denenberg JO, McClelland RL, Allison MA, Ix JH, Guerci A, et al. Abdominal aortic calcium, coronary artery calcium, and cardiovascular morbidity and mortality in the Multi-Ethnic Study of Atherosclerosis. Arterioscler Thromb Vasc Biol. 2014;34(7):1574-9.

9. Shaw LJ, Raggi P, Schisterman E, Berman DS, Callister TQ. Prognostic value of cardiac risk factors and coronary artery calcium screening for all-cause mortality. Radiology. 2003;228(3):826-33.

10. Kondos GT, Hoff JA, Sevrukov A, Daviglus ML, Garside DB, Devries SS, et al. Electron-beam tomography coronary artery calcium and cardiac events: a 37-month follow-up of 5635 initially asymptomatic low- to intermediate-risk adults. Circulation. 2003;107(20):2571-6.

11. Ho CY, Shanahan CM. Medial arterial calcification: an overlooked player in peripheral arterial disease. Arterioscler Thromb Vasc Biol. 2016;36(8):1475-82.

12. Lanzer P, Boehm M, Sorribas $V$, Thiriet M, Janzen J, Zeller T, et al. Medial vascular calcification revisited: review and perspectives. Eur Heart J. 2014;35(23):1515-25.

13. Bastos Goncalves F, Voute MT, Hoeks SE, Chonchol MB, Boersma $\mathrm{EE}$, Stolker RJ, et al. Calcification of the abdominal aorta as an independent predictor of cardiovascular events: a meta-analysis. Heart. 2012;98(13):988-94

14. Horvath S. DNA methylation age of human tissues and cell types. Genome Biol. 2013;14(10):R115.

15. Hannum G, Guinney J, Zhao L, Zhang L, Hughes G, Sadda S, et al. Genome-wide methylation profiles reveal quantitative views of human aging rates. Mol Cell. 2013;49(2):359-67.

16. Liu Z, Leung D, Thrush K, Zhao W, Ratliff S, Tanaka T, et al. Underlying features of epigenetic aging clocks in vivo and in vitro. Aging Cell. 2020;19(10):e13229.

17. Lu AT, Quach A, Wilson JG, Reiner AP, Aviv A, Raj K, et al. DNA methylation GrimAge strongly predicts lifespan and healthspan. Aging (Albany NY). 2019;11(2):303-27.

18. Fransquet PD, Wrigglesworth J, Woods RL, Ernst ME, Ryan J. The epigenetic clock as a predictor of disease and mortality risk: a systematic review and meta-analysis. Clin Epigenetics. 2019;11(1):62. 
19. Levine ME, Lu AT, Quach A, Chen BH, Assimes TL, Bandinelli S, et al. An epigenetic biomarker of aging for lifespan and healthspan. Aging (Albany NY). 2018;10(4):573-91.

20. Rask-Andersen M, Martinsson D, Ahsan M, Enroth S, Ek WE, Gyllensten $U$, et al. Epigenome-wide association study reveals differential DNA methylation in individuals with a history of myocardial infarction. Hum Mol Genet. 2016;25(21):4739-48.

21. Fernández-Sanlés A, Sayols-Baixeras S, Subirana I, Sentí M, Pérez-Fernández S, de Moura MC, et al. DNA methylation biomarkers of myocardial infarction and cardiovascular disease. bioRxiv. 2020:707315.

22. Nakatochi M, Ichihara S, Yamamoto K, Naruse K, Yokota S, Asano H, et al. Epigenome-wide association of myocardial infarction with DNA methylation sites at loci related to cardiovascular disease. Clin Epigenet. 2017:9:54.

23. Agha $G$, Mendelson MM, Ward-Caviness CK, Joehanes R, Huan T, Gondalia R, et al. Blood leukocyte DNA methylation predicts risk of future myocardial infarction and coronary heart disease. Circulation. 2019;140(8):645-57.

24. Horvath S, Gurven M, Levine ME, Trumble BC, Kaplan H, Allayee H, et al. An epigenetic clock analysis of race/ethnicity, sex, and coronary heart disease. Genome Biol. 2016;17(1):171.

25. Hillary RF, Stevenson AJ, McCartney DL, Campbell A, Walker RM, Howard DM, et al. Epigenetic measures of ageing predict the prevalence and incidence of leading causes of death and disease burden. Clin Epigenet. 2020;12(1):115.

26. Wang C, Ni W, Yao Y, Just A, Heiss J, Wei Y, et al. DNA methylation-based biomarkers of age acceleration and all-cause death, myocardial infarction, stroke, and cancer in two cohorts: The NAS, and KORA F4. EBioMedicine. 2020;63:103151

27. Liu Y, Reynolds LM, Ding J, Hou L, Lohman K, Young T, et al. Blood monocyte transcriptome and epigenome analyses reveal loci associated with human atherosclerosis. Nat Commun. 2017:8(1):393.

28. Roetker NS, Pankow JS, Bressler J, Morrison AC, Boerwinkle E. Prospective study of epigenetic age acceleration and incidence of cardiovascular disease outcomes in the ARIC study (atherosclerosis risk in communities). Circ Genom Precis Med. 2018;11(3):e001937.

29. Zhang Y, Wilson R, Heiss J, Breitling LP, Saum KU, Schottker B, et al. DNA methylation signatures in peripheral blood strongly predict all-cause mortality. Nat Commun. 2017;8:14617.

30. Gao X, Jia M, Zhang Y, Breitling LP, Brenner H. DNA methylation changes of whole blood cells in response to active smoking exposure in adults: a systematic review of DNA methylation studies. Clin Epigenet. 2015;7:113.

31. Zhang Y, Schottker B, Florath I, Stock C, Butterbach K, Holleczek B, et al. Smoking-associated DNA methylation biomarkers and their predictive value for all-cause and cardiovascular mortality. Environ Health Perspect. 2016:124(1):67-74.

32. Zeilinger S, Kuhnel B, Klopp N, Baurecht H, Kleinschmidt A, Gieger C, et al. Tobacco smoking leads to extensive genome-wide changes in DNA methylation. PLoS ONE. 2013;8(5):e63812.

33. Daniels PR, Kardia SL, Hanis CL, Brown CA, Hutchinson R, Boerwinkle E, et al. Familial aggregation of hypertension treatment and control in the Genetic Epidemiology Network of Arteriopathy (GENOA) study. Am J Med. 2004;116(10):676-81.

34. Turner ST, Kardia SL, Mosley TH, Rule AD, Boerwinkle E, de Andrade M. Influence of genomic loci on measures of chronic kidney disease in hypertensive sibships. J Am Soc Nephrol. 2006;17(7):2048-55.

35. Friedewald WT, Levy RI, Fredrickson DS. Estimation of the concentration of low-density lipoprotein cholesterol in plasma, without use of the preparative ultracentrifuge. Clin Chem. 1972;18(6):499-502.

36. Ammous F, Zhao W, Ratliff SM, Kho M, Shang L, Jones AC, et al. Epigenome-wide association study identifies DNA methylation sites associated with target organ damage in older African Americans. Epigenetics. 2021;16(8):862-75.

37. Fortin JP, Fertig E, Hansen K. shinyMethyl: interactive quality control of Illumina 450k DNA methylation arrays in R. F1000Res. 2014;3:175.

38. Lehne B, Drong AW, Loh M, Zhang W, Scott WR, Tan ST, et al. A coherent approach for analysis of the Illumina HumanMethylation450 BeadChip improves data quality and performance in epigenome-wide association studies. Genome Biol. 2015;16:37.
39. Fortin JP, Triche TJ Jr, Hansen KD. Preprocessing, normalization and integration of the Illumina HumanMethylationEPIC array with minfi. Bioinformatics. 2017:33(4):558-60.

40. Niu L, Xu Z, Taylor JA. RCP: a novel probe design bias correction method for Illumina Methylation BeadChip. Bioinformatics. 2016;32(17):2659-63.

41. Houseman EA, Accomando WP, Koestler DC, Christensen BC, Marsit CJ, Nelson $\mathrm{HH}$, et al. DNA methylation arrays as surrogate measures of cell mixture distribution. BMC Bioinform. 2012;13:86.

42. Peters TJ, Buckley MJ, Statham AL, Pidsley R, Samaras K, Reginald VL, et al. De novo identification of differentially methylated regions in the human genome. Epigenet Chromatin. 2015;8:6.

43. DNA methylation age calculator. https://dnamage.genetics.ucla.edu/. Accessed 6 Nov 2020.

44. Chen BH, Marioni RE, Colicino E, Peters MJ, Ward-Caviness CK, Tsai PC, et al. DNA methylation-based measures of biological age: meta-analysis predicting time to death. Aging (Albany NY). 2016;8(9):1844-65.

45. Irizarry RA, Bolstad BM, Collin F, Cope LM, Hobbs B, Speed TP. Summaries of Affymetrix GeneChip probe level data. Nucleic Acids Res. 2003;31(4):e15.

46. Johnson WE, Li C, Rabinovic A. Adjusting batch effects in microarray expression data using empirical Bayes methods. Biostatistics. 2007;8(1):118-27.

47. Dai M, Wang P, Boyd AD, Kostov G, Athey B, Jones EG, et al. Evolving gene/transcript definitions significantly alter the interpretation of GeneChip data. Nucleic Acids Res. 2005;33(20):e175.

48. Agatston AS, Janowitz WR, Hildner FJ, Zusmer NR, Viamonte M Jr, Detrano R. Quantification of coronary artery calcium using ultrafast computed tomography. J Am Coll Cardiol. 1990;15(4):827-32.

49. Kullo IJ, Turner ST, Kardia SL, Mosley TH Jr, Boerwinkle E, de Andrade M. A genome-wide linkage scan for ankle-brachial index in African American and non-Hispanic white subjects participating in the GENOA study. Atherosclerosis. 2006;187(2):433-8.

50. Zhao Y, Evans MA, Allison MA, Bertoni AG, Budoff MJ, Criqui MH, et al. Multisite atherosclerosis in subjects with metabolic syndrome and diabetes and relation to cardiovascular events: the multi-ethnic study of atherosclerosis. Atherosclerosis. 2019:282:202-9.

51. Horvath S, Raj K. DNA methylation-based biomarkers and the epigenetic clock theory of ageing. Nat Rev Genet. 2018;19(6):371-84.

52. Nakagawa S, Schielzeth H. Repeatability for Gaussian and non-Gaussian data: a practical guide for biologists. Biol Rev Camb Philos Soc. 2010;85(4):935-56.

53. Stoffel MA, Nakagawa S, Schielzeth $H$. rptR: Repeatability estimation and variance decomposition by generalized linear mixed-effects models. Methods Ecol Evol. 2017;8(11):1639-44.

54. Storey JD, Tibshirani R. Statistical significance for genomewide studies. Proc Natl Acad Sci U S A. 2003;100(16):9440-5.

55. Team RC. R: A language and environment for statistical computing. Vienna, Austria; 2019.

56. Bates D, Mächler M, Bolker B, Walker S. Fitting linear mixed-effects models using Ime4. J Stat Softw. 2015;67(1):1-48.

57. Bernstein BE, Stamatoyannopoulos JA, Costello JF, Ren B, Milosavljevic A, Meissner A, et al. The $\mathrm{NIH}$ roadmap epigenomics mapping consortium. Nat Biotechnol. 2010;28(10):1045-8.

58. Roadmap Epigenomics C, Kundaje A, Meuleman W, Ernst J, Bilenky M, Yen A, et al. Integrative analysis of 111 reference human epigenomes. Nature. 2015;518(7539):317-30

59. Esser C. Biology and function of the aryl hydrocarbon receptor: report of an international and interdisciplinary conference. Arch Toxicol. 2012;86(8):1323-9.

60. Vogel CFA, Haarmann-Stemmann T. The aryl hydrocarbon receptor repressor - More than a simple feedback inhibitor of AhR signaling: clues for its role in inflammation and cancer. Curr Opin Toxicol. 2017:2:109-19.

61. Reynolds LM, Wan M, Ding J, Taylor JR, Lohman K, Su D, et al. DNA methylation of the aryl hydrocarbon receptor repressor associations with cigarette smoking and subclinical atherosclerosis. Circ Cardiovasc Genet. 2015;8(5):707-16.

62. Tantoh DM, Wu MC, Chuang CC, Chen PH, Tyan YS, Nfor ON, et al. AHRR cg05575921 methylation in relation to smoking and PM2.5 exposure among Taiwanese men and women. Clin Epigenet. 2020;12(1):117.

63. Novakovic B, Ryan J, Pereira N, Boughton B, Craig JM, Saffery R. Post natal stability, tissue, and time specific effects of AHRR methylation 
change in response to maternal smoking in pregnancy. Epigenetics. 2014;9(3):377-86.

64. Wiklund P, Karhunen V, Richmond RC, Parmar P, Rodriguez A, De Silva M, et al. DNA methylation links prenatal smoking exposure to later life health outcomes in offspring. Clin Epigenet. 2019;11(1):97.

65. Siemelink MA, van der Laan SW, Haitjema S, van Koeverden ID, Schaap J, Wesseling $\mathrm{M}$, et al. Smoking is associated to DNA methylation in atherosclerotic carotid lesions. Circ Genom Precis Med. 2018;11(9):e002030.

66. Besingi W, Johansson A. Smoke-related DNA methylation changes in the etiology of human disease. Hum Mol Genet. 2014;23(9):2290-7.

67. Parmar P, Lowry E, Cugliari G, Suderman M, Wilson R, Karhunen V, et al. Association of maternal prenatal smoking GFI1-locus and cardio-metabolic phenotypes in 18,212 adults. EBioMedicine. 2018;38:206-16.

68. Joubert BR, Haberg SE, Nilsen RM, Wang X, Vollset SE, Murphy SK, et al. 450K epigenome-wide scan identifies differential DNA methylation in newborns related to maternal smoking during pregnancy. Environ Health Perspect. 2012;120(10):1425-31.

69. Richmond RC, Simpkin AJ, Woodward G, Gaunt TR, Lyttleton O, McArdle WL, et al. Prenatal exposure to maternal smoking and offspring DNA methylation across the lifecourse: findings from the Avon Longitudinal Study of Parents and Children (ALSPAC). Hum Mol Genet. 2015;24(8):2201-17.

70. van der Meer LT, Jansen JH, van der Reijden BA. Gfi1 and Gfi1 b: key regulators of hematopoiesis. Leukemia. 2010;24(11):1834-43.

71. Duan Z, Zarebski A, Montoya-Durango D, Grimes HL, Horwitz M. Gfi1 coordinates epigenetic repression of p21Cip/WAF1 by recruitment of histone lysine methyltransferase G9a and histone deacetylase 1. Mol Cell Biol. 2005;25(23):10338-51.

72. Zhang Y, Yang R, Burwinkel B, Breitling LP, Brenner H. F2RL3 methylation as a biomarker of current and lifetime smoking exposures. Environ Health Perspect. 2014;122(2):131-7.

73. Maas SCE, Mens MMJ, Kuhnel B, van Meurs JBJ, Uitterlinden AG, Peters A, et al. Smoking-related changes in DNA methylation and gene expression are associated with cardio-metabolic traits. Clin Epigenet. 2020;12(1):157.

74. Breitling LP, Salzmann K, Rothenbacher D, Burwinkel B, Brenner H. Smoking, F2RL3 methylation, and prognosis in stable coronary heart disease. Eur Heart J. 2012;33(22):2841-8.

75. Zhang Y, Yang R, Burwinkel B, Breitling LP, Holleczek B, Schottker B, et al. F2RL3 methylation in blood DNA is a strong predictor of mortality. Int J Epidemiol. 2014;43(4):1215-25.

76. GTEx Consortium. The genotype-tissue expression (GTEx) project. Nat Genet. 2013:45(6):580-5.

77. Wassel CL, Pankow JS, Peralta CA, Choudhry S, Seldin MF, Arnett DK. Genetic ancestry is associated with subclinical cardiovascular disease in African-Americans and Hispanics from the multi-ethnic study of atherosclerosis. Circ Cardiovasc Genet. 2009;2(6):629-36.

78. Kawakubo M, LaBree L, Xiang M, Doherty TM, Wong ND, Azen S, et al. Race-ethnic differences in the extent, prevalence, and progression of coronary calcium. Ethn Dis. 2005;15(2):198-204.

79. Manolio TA, Arnold AM, Post W, Bertoni AG, Schreiner PJ, Sacco RL, et al. Ethnic differences in the relationship of carotid atherosclerosis to coronary calcification: the multi-ethnic study of atherosclerosis. Atherosclerosis. 2008;197(1):132-8.

80. Pamukcu B, Lip GY, Devitt A, Griffiths H, Shantsila E. The role of monocytes in atherosclerotic coronary artery disease. Ann Med. 2010;42(6):394-403.

81. Ghattas A, Griffiths HR, Devitt A, Lip GY, Shantsila E. Monocytes in coronary artery disease and atherosclerosis: where are we now? J Am Coll Cardiol. 2013;62(17):1541-51.

82. Levine ME. Assessment of epigenetic clocks as biomarkers of aging in basic and population research. J Gerontol A Biol Sci Med Sci. 2020;75(3):463-5.

83. Nelson PG, Promislow DEL, Masel J. Biomarkers for aging identified in cross-sectional studies tend to be non-causative. J Gerontol A Biol Sci Med Sci. 2020;75(3):466-72.

84. McCrory C, Fiorito G, Hernandez B, Polidoro S, O'Halloran AM, Hever A, et al. GrimAge outperforms other epigenetic clocks in the prediction of age-related clinical phenotypes and all-cause mortality. J Gerontol A Biol Sci Med Sci. 2020:76:741-9.

85. Joehanes R, Just AC, Marioni RE, Pilling LC, Reynolds LM, Mandaviya PR, et al. Epigenetic signatures of cigarette smoking. Circ Cardiovasc Genet. 2016:9(5):436-47.
86. Dugue PA, Jung CH, Joo JE, Wang X, Wong EM, Makalic E, et al. Smoking and blood DNA methylation: an epigenome-wide association study and assessment of reversibility. Epigenetics. 2020;15(4):358-68.

87. Li X, Ploner A, Wang Y, Magnusson PK, Reynolds C, Finkel D, et al. Longitudinal trajectories, correlations and mortality associations of nine biological ages across 20-years follow-up. Elife. 2020;9:e51507.

88. Bielak LF, Peyser PA. Genetics of subclinical coronary atherosclerosis. Curr Genet Med Rep. 2018;6(3):116-23.

89. Gepner AD, Young R, Delaney JA, Budoff MJ, Polak JF, Blaha MJ, et al. Comparison of carotid plaque score and coronary artery calcium score for predicting cardiovascular disease events: the multi-ethnic study of atherosclerosis. J Am Heart Assoc. 2017;6(2):e005179.

90. Wong ND, Lopez VA, Allison M, Detrano RC, Blumenthal RS, Folsom AR, et al. Abdominal aortic calcium and multi-site atherosclerosis: the multiethnic study of atherosclerosis. Atherosclerosis. 2011;214(2):436-41.

91. Onuma OK, Pencina K, Qazi S, Massaro JM, D'Agostino RB Sr, Chuang ML, et al. Relation of risk factors and abdominal aortic calcium to progression of coronary artery calcium (from the Framingham Heart Study). Am J Cardiol. 2017;119(10):1584-9.

92. Doherty TM, Tang W, Detrano RC. Racial differences in the significance of coronary calcium in asymptomatic black and white subjects with coronary risk factors. J Am Coll Cardiol. 1999;34(3):787-94.

93. Ammous F, Zhao W, Ratliff SM, Mosley TH, Bielak LF, Zhou X, et al. Epigenetic age acceleration is associated with cardiometabolic risk factors and clinical cardiovascular disease risk scores in African Americans. Clin Epigenet. 2021;13(1):55.

94. Sun YV, Turner ST, Smith JA, Hammond PI, Lazarus A, Van De Rostyne $J \mathrm{~L}$, et al. Comparison of the DNA methylation profiles of human peripheral blood cells and transformed B-lymphocytes. Hum Genet. 2010;127(6):651-8.

95. Çalışkan M, Cusanovich DA, Ober C, Gilad Y. The effects of EBV transformation on gene expression levels and methylation profiles. Hum Mol Genet. 2011:20(8):1643-52.

96. Aberg K, Khachane AN, Rudolf G, Nerella S, Fugman DA, Tischfield JA, et al. Methylome-wide comparison of human genomic DNA extracted from whole blood and from EBV-transformed lymphocyte cell lines. Eur J Hum Genet. 2012;20(9):953-5.

97. Joehanes R, Johnson AD, Barb JJ, Raghavachari N, Liu P, Woodhouse KA, et al. Gene expression analysis of whole blood, peripheral blood mononuclear cells, and lymphoblastoid cell lines from the Framingham Heart Study. Physiol Genomics. 2012;44(1):59-75.

\section{Publisher's Note}

Springer Nature remains neutral with regard to jurisdictional claims in published maps and institutional affiliations.

Ready to submit your research? Choose BMC and benefit from:

- fast, convenient online submission

- thorough peer review by experienced researchers in your field

- rapid publication on acceptance

- support for research data, including large and complex data types

- gold Open Access which fosters wider collaboration and increased citations

- maximum visibility for your research: over $100 \mathrm{M}$ website views per year

At BMC, research is always in progress.

Learn more biomedcentral.com/submissions 